\title{
Sulfur-limitation-regulated proteins in Bacillus subtilis: a two-dimensional gel electrophoresis study
}

\author{
Jean-Yves Coppée, ${ }^{1} \dagger$ Sandrine Auger, ${ }^{1}$ Evelyne Turlin, ${ }^{1}$ \\ Agnieszka Sekowska, ${ }^{1} \mathbb{S}$ Jean-Pierre Le Caer, ${ }^{2}$ Valérie Labas, ${ }^{2}$ \\ Valérie Vagner, ${ }^{3} \ddagger$ Antoine Danchin $^{1} \mathbb{S}$ and Isabelle Martin-Verstraete ${ }^{1}$
}

Author for correspondence: Isabelle Martin-Verstraete. Tel: +33 1456872 95. Fax: +3314568 8948. e-mail: iverstra@pasteur.fr

\footnotetext{
1 Unité de Régulation de I'Expression Génétique, Institut Pasteur, 28 rue du Docteur Roux, 75724 Paris Cedex 15, France

2 Neurobiologie et Diversité Cellulaire, CNRS UMR 7637, Ecole Supérieure de Physique et Chimie Industrielles de la Ville de Paris, 10 rue Vauquelin, 75005 Paris, France

3 INRA, Domaine de Vilvert, 78352 Jouy en Josas, France
}

\begin{abstract}
Little is known about the genes and enzymes involved in sulfur assimilation in Bacillus subtilis, or about the regulation of their expression or activity. To identify genes regulated by sulfur limitation, the authors used twodimensional (2D) gel electrophoresis to compare the proteome of a wild-type strain grown with either sulfate or glutathione as sole sulfur source. A total of 15 proteins whose synthesis is modified under these two conditions were identified by matrix-assisted laser desorption/ionization time of flight (MALDI TOF) mass spectrometry. In the presence of sulfate, an increased amount of proteins involved in the metabolism of $C_{1}$ units (SerA, GlyA, FolD) and in the biosynthesis of purines (PurQ, Xpt) and pyrimidines (Upp, PyrAA, PyrF) was observed. In the presence of glutathione, the synthesis of two uptake systems (DppE, SsuA), an oxygenase (SsuD), cysteine synthase (CysK) and two proteins of unknown function (Ytml, YurL) was increased. The changes in expression of the corresponding genes, in the presence of sulfate and glutathione, were monitored using slot-blot analyses and lacz fusions. The $y \mathbf{t m l}$ gene is part of a locus of 12 genes which are co-regulated in response to sulfur availability. This putative operon is activated by a LysR-like regulator, YtII. This is the first regulator involved in the control of expression in response to sulfur availability to be identified in $B$. subtilis.
\end{abstract}

Keywords: sulfur metabolism, proteome analysis, regulation

\section{INTRODUCTION}

All living organisms require sulfur for the synthesis of proteins and essential cofactors. Sulfur can be assimilated either from inorganic sources like sulfate and thiosulfate, or from organic ones like sulfate esters, sulfamates and sulfonates. In Escherichia coli, sulfate is transported into the cell and subsequently reduced to

\footnotetext{
† Present address: Genopole, Institut Pasteur, 28 rue du Docteur Roux, 75724 Paris Cedex 15, France.

¥Present address: Sir William Dunn School of Pathology, University of Oxford, Oxford OX1 3RE, UK.

\$Present address: HKU Pasteur Research Center, Dexter HC Man Building, 8 Sassoon Road, Pokfulam, Hong Kong.

Abbreviations: 2D, two-dimensional; ABC, ATP-binding cassette; DIG, digoxigenin; MALDI-TOF, matrix-assisted laser desorption/ionization time of flight.
}

sulfide, which reacts with $\mathrm{O}$-acetylserine to form cysteine. More than 20 genes involved in this process have been identified (Kredich, 1996). Most of them are positively regulated by $\mathrm{CysB}$, a transcriptional activator belonging to the LysR family of regulators. Full expression of the cysteine biosynthetic pathway requires the CysB activator, the inducer $\mathrm{N}$-acetylserine and reduced-sulfur limitation. CysB binds upstream from the -35 region of the positively regulated promoters and facilitates the formation of a transcription initiation complex in the presence of $\mathrm{N}$-acetylserine in an as yet unknown way. L-Cysteine, sulfide and thiosulfate downregulate L-cysteine biosynthesis. Sulfide and thiosulfate appear to act as anti-inducers of $\mathrm{N}$-acetylserine, while L-cysteine feedback inhibits the synthesis of $\mathrm{O}$-acetylserine (Kredich, 1996).

Under sulfate-starvation conditions, E. coli synthesizes a 
set of proteins which are absent during growth in the presence of sulfate. These proteins are involved in the biosynthesis of cysteine from sulfide and in the utilization of alternative sulfur sources such as sulfonates (Uria-Nickelsen et al., 1993). Random lacZ fusions and 2D gel electrophoresis revealed a specific increase in the synthesis of several proteins, such as oxygenases (TauD, SsuD), high-affinity uptake systems (ATP-binding cassette- $\mathrm{ABC}$ - transport systems, sulfate- and cystine-binding proteins), alkyl hydroperoxide reductase (AhpC), O-acetylserine lyase A (CysK), and of several unidentified proteins (Kertesz et al., 1993; Quadroni et al., 1996; van der Ploeg et al., 1996, 1999). Several proteins induced under sulfatestarvation conditions have also been identified in Pseudomonas aeruginosa (Hummerjohann et al., 1998; Kertesz et al., 1999; Quadroni et al., 1999).

In Bacillus subtilis, sulfate assimilation and cysteine biosynthesis may proceed via an E. coli-like pathway. The enzymes leading to the conversion of sulfate into sulfide, and to its incorporation into cysteine, are present in B. subtilis (Kunst et al., 1997; Pasternak et al., 1965). The expression of the cysH gene, which encodes 3'phosphoadenosine $5^{\prime}$-phosphosulfate sulfotransferase, was found to be repressed by both cysteine and sulfide (Mansilla \& de Mendoza, 1997). The cysH gene is the first gene of an operon which encodes a sulfate permease (CysP) and enzymes catalysing the first steps of the sulfate assimilation pathway (Mansilla \& de Mendoza, 2000). Little is known about the regulation of sulfur metabolism. In Gram-positive bacteria, a highly conserved sequence, the S-box, is located in the leader region of several operons including genes involved in the biosynthesis of methionine or cysteine. These genes are proposed to form a new regulon controlled by a global transcription-termination control system (Grundy \& Henkin, 1998).

Only a few B. subtilis genes necessary for the assimilation of sulfur from sulfonates have been identified (van der Ploeg et al., 1998). Three of them encode an $\mathrm{ABC}$ transport system (ssuBAC) and another one encodes a monooxygenase (ssuD).

To get insight into the global regulation of sulfur-related gene expression in B. subtilis, we associated the recent knowledge of the whole genome sequence (Kunst et al., 1997), the highly sensitive technique of 2D gel electrophoresis (O'Farrell, 1975) and mass spectrometry. 2D gel electrophoresis now allows the separation of more than 1000 proteins (Bernhardt et al., 1999) and many can be identified by MALDI TOF spectrometry (Shevchenko et al., 1996). We took advantage of this technique to identify proteins whose synthesis is regulated by sulfur availability in $B$. subtilis. The protein synthesis patterns of a wild-type strain grown with either sulfate or glutathione as a sulfur source were compared. Synthesis of 15 proteins was up- or down-regulated. These proteins were identified unambiguously by MALDI TOF spectrometry. For most of them, the alteration in expression of the corresponding genes under these two conditions was confirmed by slot-blot analyses or lacZ fusions.

\section{METHODS}

Bacterial strains and culture conditions. The B. subtilis strains used in this work are listed in Table 1. Experiments were carried out using B. subtilis strains grown at $37^{\circ} \mathrm{C}$ with agitation in minimal medium $\left(6 \mathrm{mM} \mathrm{K}{ }_{2} \mathrm{HPO}_{4}, 4.5 \mathrm{mM}\right.$ $\mathrm{KH}_{2} \mathrm{PO}_{4}, 0.3 \mathrm{mM}$ trisodium citrate, $5 \mathrm{mM} \mathrm{MgCl}_{2}, 22 \mathrm{mg}$ ferric ammonium citrate $\mathrm{l}^{-1}, 0 \cdot 5 \%$ glucose, $0 \cdot 1 \%$ glutamine, $100 \mathrm{mg} \mathrm{l}^{-1}$ of auxotrophic requirements). Solid medium was supplemented with $1.5 \%$ agar. The sulfur source varied in the different experiments as stated : $5 \mathrm{mM}$ taurine, $4 \mathrm{mM} \mathrm{MgSO}_{4}$, $2 \mathrm{mM}$ reduced glutathione, $1 \mathrm{mM}$ methionine, $1 \mathrm{mM}$ thiosulfate or $0.5 \mathrm{mM}$ cysteine. Antibiotics were added to the following concentrations: ampicillin, $100 \mu \mathrm{g} \mathrm{ml}^{-1}$; chloramphenicol, $5 \mu \mathrm{g} \mathrm{ml}^{-1}$; kanamycin, $5 \mu \mathrm{g} \mathrm{ml}^{-1}$; erythromycin $1 \mu \mathrm{g} \mathrm{ml}^{-1}$ plus lincomycin $25 \mu \mathrm{g} \mathrm{ml}^{-1}$. The transformation procedures used for E. coli and B. subtilis were as described previously (Sambrook et al., 1989; Kunst \& Rapoport, 1995). The integration of DNA fragments into the amyE locus by double cross-over was assessed by monitoring the loss of amylase activity (Stülke et al., 1997). All experiments were performed in accordance with the European regulation requirements concerning the use of genetically modified organisms (level 1 containment, agreement no. 2735).

Analytical 2D gel electrophoresis. B. subtilis strain 168 was grown in minimal medium using either sulfate or glutathione as sulfur source. Exponentially growing cells $(50 \mathrm{ml})$ were harvested by centrifugation and washed twice in TE buffer (10 mM Tris $\mathrm{pH} 7 \cdot 5,1 \mathrm{mM}$ EDTA). The pellet was then resuspended in $1 \mathrm{ml}$ buffer (10 $\mathrm{mM}$ Tris pH 7·5, $1 \mathrm{mM}$ EDTA, $8 \mathrm{M}$ urea, $100 \mathrm{mM}$ DTT, $1 \%$ Triton X-100, 4\% CHAPS, $2 \mathrm{mM}$ PMSF) with $15 \mu \mathrm{l}$ of a DNase $\left(1 \mathrm{mg} \mathrm{ml}^{-1}\right) / \mathrm{RNase}$ $\left(0.5 \mathrm{mg} \mathrm{ml}^{-1}\right)$ solution. After sonication, the cell debris was removed by ultracentrifugation $(60 \mathrm{~min}, 90000 \mathrm{~g})$. Proteins $(100 \mu \mathrm{g})$ were resuspended in sample buffer $(0.5 \%$ Pharmalyte 3-10, $8 \mathrm{M}$ urea, $100 \mathrm{mM}$ DTT, 2\% Nonidet P40). Isoelectric focusing was performed on Immobiline DryStrips ( $\mathrm{pH} \mathrm{4-7)}$ with the IPGPhor Isoelectric System (Pharmacia). Strips rehydrated for $4 \mathrm{~h}$ at $20^{\circ} \mathrm{C}$ were focused for $45000 \mathrm{Vh}$. Separation in the second dimension was performed with $11.5 \%$ SDS-polyacrylamide gels. The gels were fixed in $40 \%$ ethanol $/ 10 \%$ acetic acid and silver-stained. The gels were digitized using a JX-330 scanner (Sharp). Spot detection and quantification were performed using the PDQUEST software package (Bio-Rad).

MALDI-TOF spectrometry identification. Protein spots were cut off and digested in gel slices with trypsin (Roche) as described previously (Shevchenko et al., 1996). The matrix used for the desalted digestions was a saturated solution of 2,5-dihydroxybenzoic acid in $0.1 \%$ trifluoroacetic acid. MALDI-TOF spectra of the peptides were obtained with a Voyager-DE STR Biospectrometry Workstation mass spectrometer (PE Biosystems). The analysis was performed in positive ion reflector mode. The trypsin autoproteolysis products were used as internal calibrants. Data mining was performed using ProFound and MS-FIT software against nonredundant databases. A mass deviation of $0 \cdot 1-0 \cdot 3$ Da was allowed in the database searches.

Slot-blot analyses. Digoxigenin (DIG)-labelled probes corresponding to $y t m I, d p p E, p y r F$, ser $A, p u r Q, g l y A$, aroF and $u p p$ were obtained using the PCR DIG probe synthesis kit 
Table 1. Bacterial strains used in this study

\begin{tabular}{|c|c|c|}
\hline Strain & Genotype & Source* \\
\hline 168 & $\operatorname{trp} C 2$ & Laboratory stock \\
\hline BSIP1207 & $\operatorname{trp} C 2$ amyE: :cysK'-lacZ cat & pDIA5566 $\rightarrow 168$ \\
\hline BSIP1214 & $\operatorname{trp} C 2$ ytlI::aphA3 & PDIA5577 $\rightarrow 168$ \\
\hline BSIP1223 & trpC2 ytmI'-lacZ erm $\Delta y \operatorname{tmI}$ ytll::aphA3 & DNA BSIP1214 $\rightarrow$ BFS71 \\
\hline BSIP1248 & $\operatorname{trp} C 2$ amyE::ser $A^{\prime}-l a c Z$ cat & pDIA5593 $\rightarrow 168$ \\
\hline BSIP1249 & $\operatorname{trp} C 2$ ytlI::aphA3 amyE::serA'-lacZ cat & pDIA5593 $\rightarrow$ BSIP1214 \\
\hline BFS68† & $\operatorname{trp} C 2$ ytnM'-lacZ erm $\Delta y \operatorname{tnM}$ & V. Vagner \\
\hline BFS70† & $\operatorname{trp} C 2$ ytnJ'-lacZ erm $\Delta y t n J$ & V. Vagner \\
\hline BFS71† & trpC2 ytmI'-lacZerm $\Delta y$ tmI & V. Vagner \\
\hline BFS85† & $\operatorname{trp} C 2$ ytmJ'-lacZ erm $\Delta y t m J$ & J. Chapuis \\
\hline BFS86† & $\operatorname{trp} C 2$ ytmK'-lacZ erm $\Delta y t m K$ & J. Chapuis \\
\hline BFS88+ & $\operatorname{trp} C 2$ ytm $M^{\prime}-$ lacZ erm $\Delta y t m M$ & J. Chapuis \\
\hline BFS424† & $\operatorname{trp} C 2$ ssu $A^{\prime}-$ lacZ erm $\Delta s s u A$ & L. A. Rivas \\
\hline BFS1249† & $\operatorname{trp} C 2$ yurL'-lacZ erm $\triangle y u r L$ & M. F. Hullo \\
\hline LCC1 & $a m y E:: x p t^{\prime}-l a c Z c a t$ & H. Saxild \\
\hline
\end{tabular}

*Arrows indicate construction by transformation; cat is the pC194 chloramphenicol acetyltransferase gene; aphA3 is the Enterococcus faecalis kanamycin-resistance gene and erm is an erythromycinresistance gene. M. F. Hullo, Institut Pasteur, Paris, France; V. Vagner and J. Chapuis, INRA, Jouy en Josas, France; L. A. Rivas, CSIC, Cantoblanco, Madrid, Spain; H. Saxild, Technical University, Lyngby, Denmark.

† These strains were constructed within the framework of the EC project for functional characterization of the genome of B. subtilis (http://locus.jouy.inra.fr/cgi-bin/genmic/madbase/progs/ madbase.operl).

from Roche. Total RNA was extracted from exponentially growing cells using the High Pure RNA Isolation Kit (Roche). Increasing amounts $(50,100,200$ and $400 \mathrm{ng})$ of total RNA were transferred to a positively charged nylon membrane and hybridized with the DIG-labelled probes. Chemiluminescent detection was performed with anti-DIG-AP and CDP-Star (Roche). The chemiluminescent signal was detected on X-ray film. Slot-blots were analysed and quantified using the Image Master 1D software from Pharmacia.

Plasmid constructs. A 1055 bp DNA fragment containing part of the $y t l l$ gene from position -209 to +846 (numbering is relative to the translational start site) was amplified by PCR using chromosomal DNA as template and two specific primers containing an EcoRI or a BamHI restriction site. The EcoRI-BamHI fragment was cloned into the pJH101 vector (Ferrari et al., 1983) to give pDIA5576. A $1.5 \mathrm{~kb}$ ClaI DNA fragment corresponding to the kanamycin-resistance gene $a p h A 3$ was inserted at the unique ClaI site of pDIA5576. The resulting plasmid pDIA5577 linearized with $S c a$ I was used to transform B. subtilis 168, leading to the disruption of the $y t l I$ gene by insertion of a kanamycin cassette (Table 1 ).

A 336 bp and a 474 bp DNA fragment corresponding to the serA promoter (from position -270 to +66 relative to the translational start site) and to the cysK promoter (from position -210 to +264 relative to the translational start site) was amplified by PCR. Oligonucleotides were used to create an EcoRI restriction site at the $5^{\prime}$ end and a BamHI restriction site at the $3^{\prime}$ end of the fragments. After digestion of the PCR products with BamHI and EcoRI, they were inserted into plasmid pAC6 (Stülke et al., 1997). The resulting serA-lacZ and cysK-lac $Z$ fusions were subsequently integrated at the amyE locus (Table 1).
Within the framework of a European project on the functional analysis of the genome of $B$. subtilis, more than 1100 genes have been disrupted by fusion with the lac $Z$ reporter gene (see http : / locus.jouy.inra.fr/cgi-bin / genmic/madbase/progs / madbase.operl). An internal fragment of each gene was amplified by PCR using primers creating HindIII and BamHI restriction sites at the $5^{\prime}$ and $3^{\prime}$ ends of the PCR product, respectively. After digestion with HindIII and BamHI, these PCR products were cloned into the pMUTIN4 vector (Vagner et al., 1998). The pMUTIN derivatives were then integrated into the $B$. subtilis chromosome by homologous recombination at the target locus. This strategy was used to inactivate $y u r L, s s u A$ and six genes of the $y t m I$ locus while creating a lacZ fusion (see Table 1).

$\boldsymbol{\beta}$-Galactosidase assays. Cells were grown in minimal medium in the presence of different sulfur sources. Samples of the cultures were taken during exponential growth and harvested by centrifugation. The $\beta$-galactosidase activity was measured using the Miller assay (Miller, 1972) with cell extracts obtained by lysozyme treatment. All the assays were repeated at least twice. One unit (U) of $\beta$-galactosidase is defined as the amount of enzyme which produces $1 \mathrm{nmol} o$-nitrophenol $\min ^{-1}$ at $28^{\circ} \mathrm{C}$.

\section{RESULTS}

\section{Comparison of the protein synthesis patterns of $B$. subtilis cells grown with sulfate or glutathione as sulfur source}

Using 2D electrophoresis, the protein synthesis pattern of a wild-type $B$. subtilis strain grown on minimal medium in the presence of different sulfur sources was 
(a)

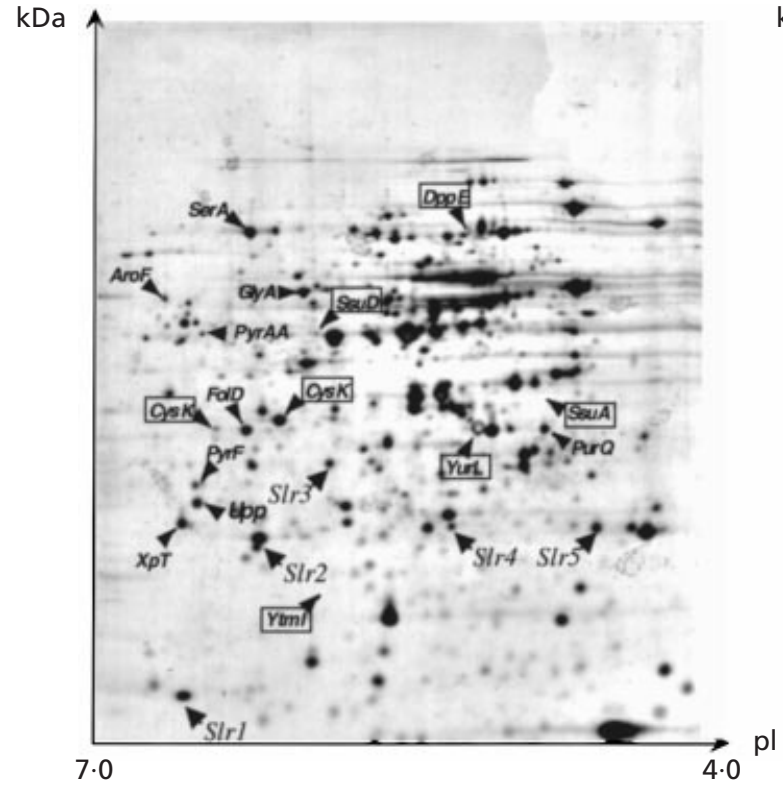

(b)

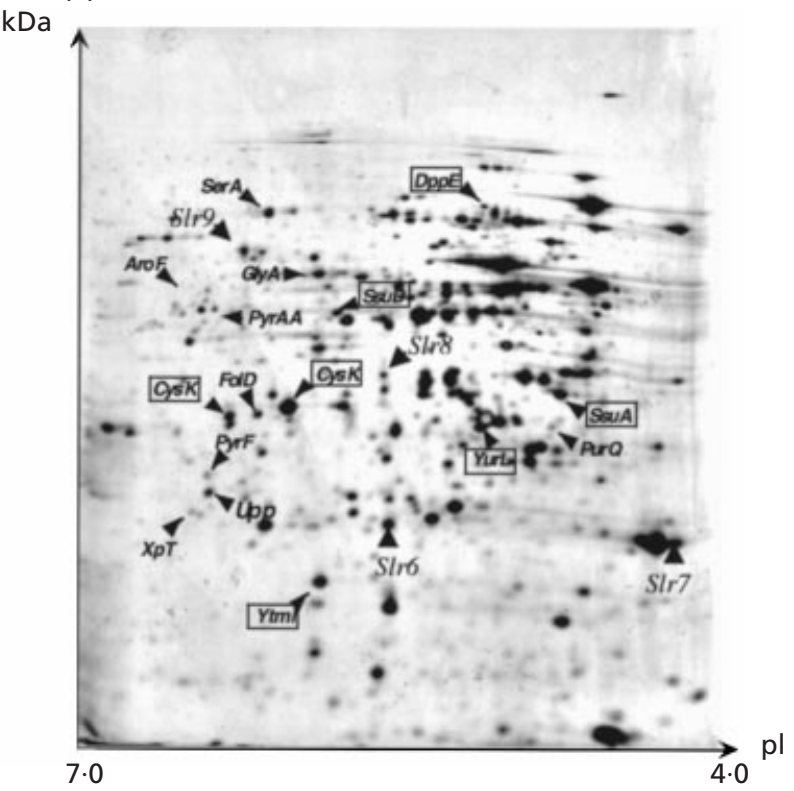

Fig. 1. Comparison of the protein synthesis patterns of $B$. subtilis 168 after growth in the presence of glutathione or sulfate. Cells were grown exponentially in minimal medium supplemented with $50 \mu \mathrm{g}$ tryptophan $\mathrm{ml}^{-1}$ and either (a) $4 \mathrm{mM}$ sulfate or (b) $2 \mathrm{mM}$ glutathione at $37^{\circ} \mathrm{C}$. Proteins were separated with IPG pH 4-7 in the first dimension and with $11.5 \%$ polyacrylamide gel in the second dimension. After silver staining, proteins regulated by the sulfur source were submitted to MALDI TOF spectrometry. The proteins identified as being more abundant after growth with glutathione are boxed. The protein names are according to SubtiList (http://genolist.pasteur.fr/SubtiList). The proteins which could not be identified by MALDI spectrometry are named SIr (sulfur-limitation-regulated). The CysK protein is identified at two different positions on the gel. Post-translational modification of this protein is possible.

Table 2. Sulfur-regulated proteins identified by 2D gel analysis

Proteins were selected by computer-assisted comparison of silver-stained gels and identified by MALDI TOF spectrometry. The results are representative of four independent experiments. G, glutathione; S, sulfate.

\begin{tabular}{|c|c|c|c|c|c|}
\hline \multicolumn{3}{|c|}{ Glutathione } & \multicolumn{3}{|c|}{ Sulfate } \\
\hline Gene & Protein & Synthesis & Gene & Protein & Synthesis \\
\hline$y t m I$ & Unknown & $\begin{array}{l}\text { Induced on } \mathrm{G} / \mathrm{absent} \\
\text { on } \mathrm{S}\end{array}$ & $x p t$ & Xanthine phosphoribosyltransferase & $\begin{array}{l}\text { 6-fold higher on } S \\
\text { than on } G\end{array}$ \\
\hline yurL & Unknown & $\begin{array}{l}\text { Induced on G/absent } \\
\text { on } S\end{array}$ & purQ & $\begin{array}{l}\text { Phosphoribosylformylglycinamidine } \\
\text { synthase I }\end{array}$ & $\begin{array}{l}\text { 5-fold higher on } S \\
\text { than on } G\end{array}$ \\
\hline $\operatorname{ssuA}$ & $\begin{array}{l}\text { Aliphatic sulfonates } \mathrm{ABC} \\
\text { transporter }\end{array}$ & $\begin{array}{l}\text { Induced on G/absent } \\
\text { on } S\end{array}$ & $u p p$ & Uracil phosphoribosyltransferase & $\begin{array}{l}\text { 2-fold higher on } S \\
\text { than on } G\end{array}$ \\
\hline $\operatorname{ssuD}$ & $\begin{array}{l}\text { Aliphatic sulfonates } \\
\text { monooxygenase }\end{array}$ & $\begin{array}{l}\text { Induced on G/absent } \\
\text { on } S\end{array}$ & pyrAA & Carbamoyl-phosphate synthase & $\begin{array}{l}\text { Induced on } \\
\text { S/absent on G }\end{array}$ \\
\hline$d p p E$ & Dipeptide $\mathrm{ABC}$ transporter & $\begin{array}{l}\text { Induced on G/absent } \\
\text { on } S\end{array}$ & pyrF & Orotidylate decarboxylase & $\begin{array}{l}\text { Induced on } \\
\text { S/absent on G }\end{array}$ \\
\hline \multirow[t]{4}{*}{$c y s K$} & Cysteine synthase & $\begin{array}{l}\text { 5-fold higher on } G \\
\text { than on } S\end{array}$ & $\operatorname{ser} A$ & Phosphoglycerate dehydrogenase & $\begin{array}{l}\text { 2-fold higher on } S \\
\text { than on } G\end{array}$ \\
\hline & & & $g l y A$ & Serine hydroxymethyltransferase & $\begin{array}{l}\text { 2-fold higher on } S \\
\text { than on } G\end{array}$ \\
\hline & & & fold & $\begin{array}{l}\text { Methylenetetrahydrofolate } \\
\text { dehydrogenase }\end{array}$ & $\begin{array}{l}\text { 2-fold higher on } S \\
\text { than on } G\end{array}$ \\
\hline & & & aroF & 3-Dehydroquinate dehydratase & $\begin{array}{l}\text { Induced on } \\
\text { S/absent on G }\end{array}$ \\
\hline
\end{tabular}


analysed. Significant differences were observed in the growth of the strain in media with the different sulfur sources: the generation time was $50 \mathrm{~min}$ with sulfate, $55 \mathrm{~min}$ with methionine, $155 \mathrm{~min}$ with taurine and 180 min with glutathione. The utilization of glutathione as sulfur source corresponds to sulfur-limitation conditions. Furthermore, it alleviates the problems linked to the use of taurine, which behaves like an ampholyte and is therefore difficult to use in 2D experiments.

To create a $2 \mathrm{D}$ reference map, the experimental conditions optimizing gel resolution and MALDI TOF spectrometry identification rates were established (See Methods). We identified 47 spots which were used as markers allowing the comparison of our gels with other B. subtilis 2D gels available on the internet (http:// microbio2.biologie.uni-greifswald.de:8880/). Furthermore, these markers facilitate the prediction of the molecular mass and the isoelectric point of a spot according to its position on the gel. These reference spots represent proteins involved mainly in the metabolism of carbohydrates, lipids or $\mathrm{C}_{1}$ units, in the biosynthesis of nucleotides, or in response to stress and in oxidative phosphorylations (data not shown).

We then compared the protein synthesis patterns (proteome) of the wild-type strain grown on sulfate or glutathione. For both sulfur sources, two independent protein preparations were made and for each preparation at least two gels were run, silver-stained and analysed. This allowed us to identify 24 proteins whose synthesis was up- or down-regulated (by at least a factor of 2) in the presence of one of these sulfur sources (Fig. 1 ). The synthesis of 10 proteins was increased in the presence of glutathione while 14 others were more abundant in the presence of sulfate (Fig. 1). These 24 spots were cut out of the gel, digested with trypsin and submitted to MALDI TOF spectrometry. In these conditions, 15 spots were unambigously identified (Table 2) while 9 others remained unidentified. In the presence of glutathione, a significant increase in the synthesis of uptake systems (DppE, SsuA), of an oxygenase $(\mathrm{SsuD})$, of two proteins of unknown function (YtmI, YurL) and of cysteine synthase (CysK) was observed. After growth with sulfate, the amount of proteins involved in the metabolism of $\mathrm{C}_{1}$ units (SerA, GlyA, FolD), in the biosynthesis of purines (PurQ, Xpt) and pyrimidines (Upp, PyrAA, PyrF) and in the biosynthesis of chorismate (AroF) was increased (Table 2). However, the alteration in synthesis of these proteins could be due either to the regulation in response to sulfur limitation or to a more general effect related to the reduction of growth rate.

Slot-blot analysis was used to determine if the changes in the quantities of GlyA, SerA, Fold, PurQ, Upp, PyrAA and PyrF observed by 2D gel analysis resulted from altered transcription of the corresponding genes. Total RNA was extracted after growth of strain 168 in minimal medium containing glutathione or sulfate. Increasing amounts of these RNAs were hybridized with DIG-labelled probes covering serA, glyA, folD, purQ,
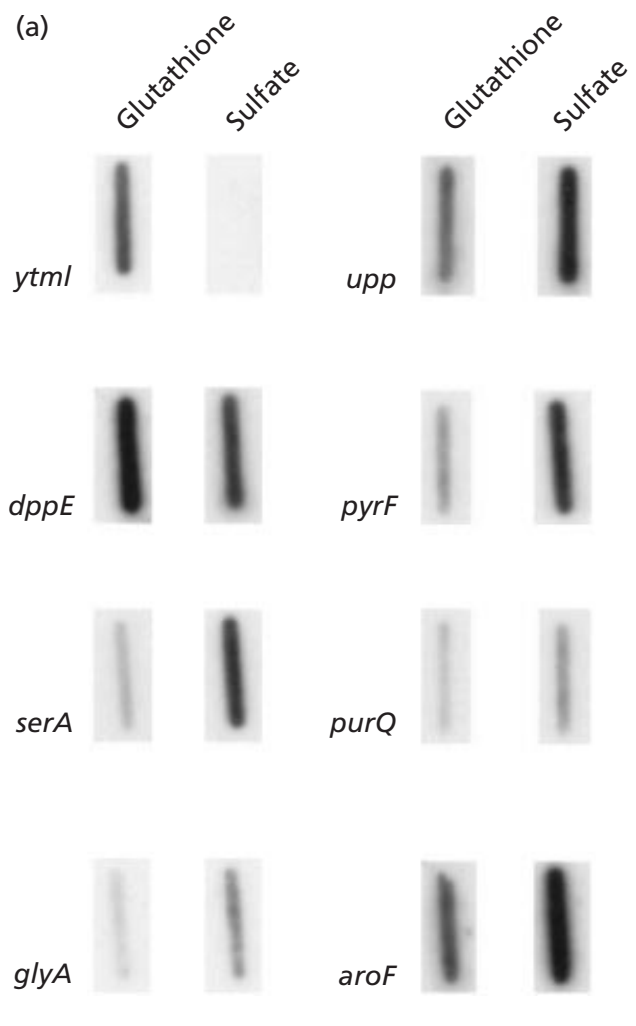

(b)

\begin{tabular}{|c|l|}
\hline Gene & Slot-blot intensity \\
\hline ytml & Absent on S/induced on $\mathrm{G}$ \\
\hline$d p p E$ & 1.5 times more intense on $\mathrm{G}$ \\
\hline purQ & 1.7 times more intense on $\mathrm{S}$ \\
\hline upp & 2 times more intense on $\mathrm{S}$ \\
\hline pyrF & 2 times more intense on $\mathrm{S}$ \\
\hline serA & 5 times more intense on S \\
\hline glyA & 3.5 times more intense on S \\
\hline aroF & 1.8 times more intense on $\mathrm{G}$ \\
\hline
\end{tabular}

Fig. 2. Quantitative analyses of the expression of the genes regulated by the sulfur source. (a) Slot-blot analyses. Total RNAs were extracted after growth on minimal medium supplemented with sulfate or glutathione. Various amounts (50 ng for purQ; $100 \mathrm{ng}$ for glyA; $200 \mathrm{ng}$ for serA, pyrF; $400 \mathrm{ng}$ for ytml, dppE, upp and aroF) of RNAs were blotted onto nylon membranes and hybridized with DIG-labelled probes specific for the genes indicated. (b) Quantification of the transcription levels. The chemiluminescent signals of the slot-blots were quantified using the Image Master 1D software. The ratios between means from two independent experiments were calculated for each gene and each growth condition.

$u p p, p y r F$ and $\operatorname{aroF}$ (Fig. 2a and data not shown). In the presence of sulfate, the expression of the $\operatorname{ser} A, g l y A$, purQ, upp, pyrF and aroF genes was increased 5-, 3.5-, $1 \cdot 7-, 2-, 2-$ and 1.8-fold, respectively, as compared to their expression in the presence of glutathione (Fig. 2b). No detectable variation was observed in the folD transcription level (data not shown). The $\beta$-galactosidase activity of a strain carrying an $x p t-l a c Z$ fusion was also 3 -fold higher during growth in the presence of 
Table 3. Effect of different sulfur sources on the growth rates of the wild-type and $\Delta y t m /$ mutant and on the expression of a ytml-lacZ fusion in different backgrounds

IPTG was added to the medium. The pspac promoter controls the transcription of the genes downstream of $y t m I$ in an IPTGdependent fashion (Vagner et al., 1998). The $\beta$-galactosidase activities were obtained from cultures in the middle of exponential growth. These values represent means of at least two independent experiments.

\begin{tabular}{|c|c|c|c|c|}
\hline \multirow{2}{*}{$\begin{array}{l}\text { Sulfur } \\
\text { source }\end{array}$} & \multicolumn{2}{|c|}{ Generation time (min) } & \multicolumn{2}{|c|}{$\beta$-Galactosidase activity $\left[\mathrm{U}(\mathrm{mg} \text { protein })^{-1}\right]$} \\
\hline & Wild-type (168) & $\Delta y t m I(B F S 71)$ & ytmI-lacZ (BFS71) & ytmI-lacZ $\Delta y t l I$ (BSIP1223) \\
\hline Glutathione & 180 & 190 & 2481 & 27 \\
\hline Taurine & 155 & $>500$ & 2170 & 12 \\
\hline Methionine & 55 & 55 & 2065 & 30 \\
\hline Sulfate & 50 & 50 & 7 & $1 \cdot 6$ \\
\hline Cysteine & 80 & 80 & 3 & $1 \cdot 3$ \\
\hline Thiosulfate & 55 & 55 & $3 \cdot 2$ & $1 \cdot 3$ \\
\hline
\end{tabular}

sulfate when compared to the activity measured in the presence of glutathione $\left[300 \mathrm{U}(\mathrm{mg} \text { protein })^{-1}\right.$ and $95 \mathrm{U}$ (mg protein $)^{-1}$, respectively]. The modification of expression of these genes in the two conditions tested seems to occur at the transcriptional level.

\section{Increased synthesis of proteins involved in sulfur metabolism in the presence of glutathione}

In $B$. subtilis, the synthesis of three proteins clearly involved in sulfur metabolism (CysK, SsuA and SsuD) was enhanced in the presence of glutathione.

Cysteine synthase, CysK, catalyses the synthesis of Lcysteine from sulfide and O-acetylserine (Kredich, 1996). The amount of this protein was increased fivefold in the presence of glutathione as revealed by 2D gel analysis (Table 2). To test the regulation of expression of the cysK gene, strain BSIP1207, carrying a cysK-lacZ transcriptional fusion, was constructed. This strain was grown in minimal medium in the presence of sulfate or glutathione as sulfur source. $\beta$-Galactosidase activity was $265 \mathrm{U}$ (mg protein) ${ }^{-1}$ after growth in the presence of glutathione compared to $50 \mathrm{U}$ (mg protein) ${ }^{-1}$ in the presence of sulfate. A comparable repression was observed after growth in the presence of cysteine [the $\beta$ - galactosidase activity was $28 \mathrm{U}$ (mg protein $)^{-1}$.

The SsuA and SsuD proteins are involved in the utilization of sulfonates in B. subtilis (van der Ploeg et al., 1998). SsuA is the binding protein of an ABC permease system for aliphatic sulfonates and SsuD is likely to be a monooxygenase (Eichhorn et al., 1999). These two proteins were not detected after growth with sulfate (Fig. 1, Table 2). The expression of an ssuA-lacZ fusion appeared to be upregulated 600-fold in the presence of glutathione and 1000-fold in the presence of methionine when compared with its expression level in the presence of sulfate. The $\beta$-galactosidase activities measured in the presence of these sulfur sources were 1109, 1646 and $1.6 \mathrm{U}$ (mg protein) ${ }^{-1}$, respectively. The regulation of this operon is therefore likely to occur at the transcriptional level, as previously observed (van der Ploeg et al., 1998).

DppE, the dipeptide-binding protein of the high-affinity ABC permease of dipeptides (Mathiopoulos et al., 1991), was also more abundant in cells grown on glutathione than in those grown on sulfate. Slot-blot analysis performed with a probe covering $d p p E$ revealed a slight induction of this gene: its expression was increased only 1.5-fold with glutathione as compared to its expression with sulfate (Fig. 2).

Two proteins of unknown function, YtmI and YurL, were detected on 2D gels only in extracts obtained after growth with glutathione (Fig. 1). YurL shares sequence similarities with the PfkB family of carbohydrate kinases (Wu et al., 1991). Using a strain carrying a yurL-lacZ fusion the expression of this gene was shown to be induced 40 -fold on glutathione [430 $\mathrm{U}(\mathrm{mg} \text { protein })^{-1}$ ] as compared to its expression on sulfate $[10 \mathrm{U} / \mathrm{mg}$ protein) ${ }^{-1}$. Expression of yurL is thus strongly derepressed at the transcriptional level during sulfur limitation.

\section{Coordinated regulation of the ytml locus}

The synthesis of the YtmI protein is strongly increased in the presence of glutathione. The regulation of expression of the corresponding gene and the genetic organization of the $y \mathrm{tmI}$ region were therefore studied in more detail. In order to investigate the regulation of the $y t m I$ gene in response to sulfur availability, a fusion between the $y t m I$ and $l a c Z$ genes was constructed. Strain BFS71 contains a $y$ tmI-lacZ transcriptional fusion and a $y$ tmI gene disruption (Table 1). The effect of several sulfur sources on the expression of this fusion was tested (Table 3). The $\beta$-galactosidase activity of strain BFS71 after growth on glutathione was 350 -fold higher than that after growth on sulfate. This result confirms the data obtained by 2D gel analysis and indicates that expression of the $y \mathrm{tmI}$ gene is regulated at the transcriptional level. The expression of this gene was also 
(a)

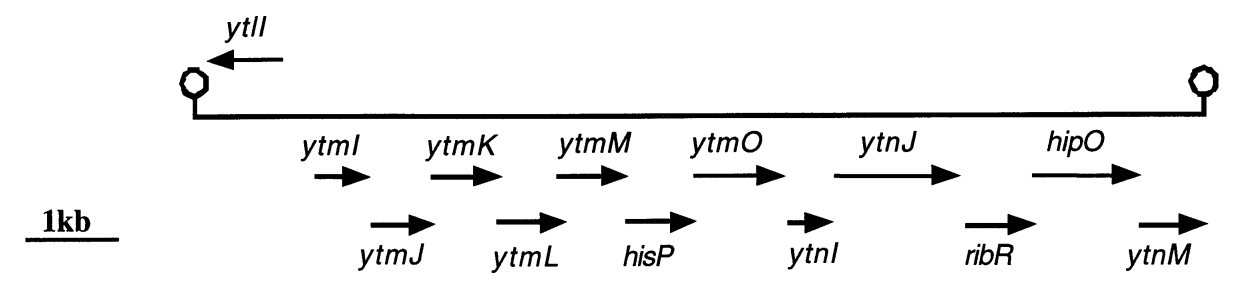

(b)

\begin{tabular}{|c|c|c|c|c|c|}
\hline \multirow[b]{2}{*}{ Gene } & \multirow[b]{2}{*}{ Protein } & \multicolumn{4}{|c|}{ Induction } \\
\hline & & Sulfate & Glutathione & Methionine & Taurine \\
\hline$y t l I$ & $\begin{array}{l}\text { unknown; similar to transcriptional regulator } \\
\text { (LysR family) }\end{array}$ & nd & nd & nd & nd \\
\hline$y t m I$ & unknown & - & ++ & ++ & ++ \\
\hline$y t m J$ & $\begin{array}{l}\text { similar to amino acid } \mathrm{ABC} \text { transporter } \\
\text { (binding protein) }\end{array}$ & - & + & ++ & ++ \\
\hline$y \operatorname{tm} K$ & $\begin{array}{l}\text { similar to amino acid } \mathrm{ABC} \text { transporter } \\
\text { (binding protein) }\end{array}$ & - & + & ++ & ++ \\
\hline$y t m L$ & $\begin{array}{l}\text { similar to amino acid } \mathrm{ABC} \text { transporter } \\
\text { (permease) }\end{array}$ & nd & nd & nd & nd \\
\hline$y t m M$ & $\begin{array}{c}\text { similar to amino acid } \mathrm{ABC} \text { transporter } \\
\text { (permease) }\end{array}$ & - & + & ++ & ++ \\
\hline hisP & $\begin{array}{l}\text { histidine transport protein (ATP-binding } \\
\text { protein) }\end{array}$ & nd & nd & nd & nd \\
\hline$y \operatorname{tmO}$ & unknown & nd & nd & nd & nd \\
\hline$y \operatorname{tnI}$ & unknown & nd & nd & nd & nd \\
\hline$y \operatorname{tnJ}$ & similar to nitrilotriacetate monooxygenase & - & ++ & ++ & ++ \\
\hline ribR & riboflavin kinase & nd & nd & nd & nd \\
\hline hipO & hippurate hydrolase & nd & nd & nd & nd \\
\hline$y \operatorname{tn} M$ & unknown & - & + & ++ & ++ \\
\hline
\end{tabular}

Fig. 3. Analysis of the chromosomal region containing ytml. (a) Organization of the ytml locus. For each gene, the direction of transcription is indicated by an arrow whose size is proportional to the length of the corresponding gene. Putative transcription terminators are represented by loops. (b) Sulfur regulation of the genes located at the ytml locus. For each gene product, similarities with proteins of known function are indicated according to SubtiList (http://genolist.pasteur.fr/SubtiList). When lacZ fusions were available, the expression of these genes was analysed on solid minimal medium supplemented with sulfate, glutathione, methionine or taurine as sole sulfur source $(-$, no expression; +, weak expression; ++ , high expression; nd, not determined).

strongly increased in the presence of taurine, isethionate, methanesulfonate and methionine (Table 3 and data not shown). In contrast, the transcription of $y \mathrm{tmI}$ appeared to be very weak in the presence of sulfate, thiosulfate and cysteine (Table 3 ).

The $y t m I$ gene belongs to a locus of 12 genes which are transcribed in the same direction (Fig. 3a). No terminator could be identified within this locus, suggesting that it forms an operon (d'Aubenton Carafa et al., 1990). Transcriptional fusions of $l a c Z$ and $y t m J, y t m K, y t m M$, $y t n J$ or $y t n M$ were constructed as described for $y t m I$ (Table 1). These fusions were tested on plates containing minimal medium supplemented with sulfate, glutathione, methionine or taurine as sole sulfur source. For all the fusions tested, we observed a minimal expression level in the presence of sulfate and a clear increase in expression with taurine, glutathione or methionine (Fig. $3 \mathrm{~b})$. These results indicate a co-regulation of all these genes. In contrast, the $y$ toI-lacZ fusion (ytoI is downstream of $y \operatorname{tn} M$ ) did not respond to any regulation by the sulfur source. These results strongly suggest the existence of a large operon (from ytmI to $y \operatorname{tn} M$ ) regulated in response to sulfur availability. The role of these genes in sulfur assimilation in B. subtilis is not yet known. However, a significant alteration of the growth on taurine of the strain carrying a $y \mathrm{tmI}$ gene disruption (BFS71) was observed, while its growth with sulfate, methionine, cysteine and thiosulfate was unaffected (Table 3). This result indicates that at least one of the genes of the $y t m I$ locus is directly or indirectly involved in the assimilation of taurine. This growth defect on taurine could be due to the involvement of $y \mathrm{tmI}$ in taurine utilization but also to polar effects on genes located downstream of $y t m I$.

The YtmJ, YtmK, YtmL, YtmM and HisP polypeptides share similarities with amino acid $A B C$ transport systems (http://www.biology.ucsd.edu/ ipaulsen/ transport). We therefore tested the possible role of this $\mathrm{ABC}$ permease in the uptake of sulfur-containing amino acids. The $y t m M$ mutant was able to grow with methionine and cysteine as sulfur sources (data not shown). This indicates either that this ABC permease is 
probably not involved in the uptake of these two amino acids or that there exist several uptake systems for these amino acids, as observed for methionine in E. coli (Greene, 1996).

\section{YtIl positively regulates the expression of the ytm gene in response to sulfur availability}

The $y t l$ gene is located upstream of $y t m I$ and is transcribed divergently. The product of the $y t l l$ gene displays significant similarities with the LysR family of transcriptional regulators. The YtlI protein might therefore encode the transcriptional activator of the $y t m I$ gene. To test this possibility, a kanamycin-resistance cassette was inserted into the ytll gene. Chromosomal DNA from strain BSIP1214 (ytlI::aphA3) was used to transform strain BFS71 containing a ytmI-lacZ fusion, resulting in strain BSIP1223. The $\beta$-galactosidase activity was measured after growth of the wild-type strain and the $y t l l$ mutant in the presence of various sulfur sources (Table 3). Disruption of the $y t l I$ gene led to the complete loss of $y t m I$ expression in the presence of methionine, taurine or glutathione as sulfur source. This indicates that $y t l I$ positively regulates the expression of $y \mathrm{tmI}$ in response to the availability of sulfur sources. The $y t l I$ gene probably controls the expression of the entire $y t m I$ locus. Indeed, when $y t l I$ is disrupted, we also observed lack of expression of the $y t n J$ and $y t m O$ genes in the presence of either taurine, glutathione or methionine (data not shown). The involvement of YtlI in the regulation of the expression of the $\operatorname{ser} A, \operatorname{gly} A, \operatorname{ssu} A$, cysK and yurL genes was also investigated. The inactivation of $y t l l$ did not modify the expression pattern of serA-lacZ, ssuA-lacZ, yurL-lacZ and cysK-lacZ fusions (data not shown). Slot-blot analyses revealed that YtII does not regulate the expression of glyA. Indeed, this expression remained 3.5-fold higher on sulfate than on glutathione if $y t l I$ was inactivated (data not shown). One may therefore conclude that YtlI is probably not involved in the global regulation of transcription of these genes in response to sulfur availability.

\section{DISCUSSION}

The metabolism of sulfur in Gram-positive bacteria remains poorly understood despite its importance for the synthesis of many cofactors and amino acids. To get insight into the sulfur metabolism of $B$. subtilis, we have compared the proteome of a wild-type strain grown with either sulfate or glutathione as sole sulfur source. Glutathione occurs in animal tissues, plants and many micro-organisms in significant concentrations (Meister, 1988). In higher eukaryotes, reduced glutathione is metabolized by peptide cleavage, which yields glycine and cysteine. In B. subtilis, the transport and metabolic pathways of glutathione are not clear (Sekowska et al., 2000). Glutathione is probably slowly degraded into cysteine, so that growth with this sulfur source induces the expression of sulfur-scavenging proteins in E. coli and B. subtilis (van der Ploeg et al., 1997, 1998).
Using MALDI TOF spectrometry, 15 proteins whose synthesis is up- or down-regulated by sulfate or glutathione have been identified. Nine other sulfur-limitationregulated (Slr) proteins remained unidentified. For seven of them, this could be attributed to their low molecular mass $(25 \mathrm{kDa})$. In the presence of sulfate, the amount of proteins involved in the metabolism of $\mathrm{C}_{1}$ units (SerA, GlyA, FolD), in the biosynthesis of nucleotides (PurQ, Upp, PyrAA, PyrF, Xpt) and in the synthesis of chorismate (AroF) is increased. However, the increase of expression of the corresponding genes is weak (Fig. 2). At this time, it is difficult to discriminate between a modification of expression due to differences in the growth rate, a general derepression during nutrient starvation or a specific regulation during sulfur limitation.

Analysis of the proteome of the wild-type strain grown in the presence of glutathione revealed that the synthesis of at least six proteins is significantly enhanced. Five of them are related to $\mathrm{ABC}$ transport and/or desulfonation systems: SsuA, SsuD, DppE, YurL and YtmI. ABC permeases which actively transport substrates (e.g. sugars, amino acids, peptides) across biological membranes (Quentin et al., 1999) probably play an essential role in the adaptation of $B$. subtilis to its environment.

The $y u r L$ gene is located in the yurONML region. These genes encode proteins sharing similarities with sugar ABC permeases and sugar kinases. Surprisingly, YurL contains six cysteine residues while all the other proteins induced by glutathione contain no or one cysteine residue, like the majority of the $B$. subtilis proteins (Danchin et al., 2000). A similar specific induction of proteins containing very few cysteine residues under sulfur limitation conditions had been previously described for E. coli (van der Ploeg et al., 1996) and Calothrix (Mazel \& Marlière, 1989). The up-regulation of a cysteine-rich protein such as YurL under sulfurlimiting conditions might not be specific for sulfur deprivation but reflect a more general induction due to nutrient limitation.

The $d p p E$ gene belongs to an operon encoding an ABC permease for dipeptides (Mathiopoulos et al., 1991). This operon, which is upregulated rapidly after induction of sporulation, may facilitate adaptation to nutrient limitation instead of favouring sporulation. The regulation of $d p p E$ expression might be a way for the cell to scavenge sulfur-containing peptides in response to sulfur limitation.

Proteins directly related to sulfur metabolism are also more abundant in the presence of glutathione: CysK, SsuA and SsuD. CysK, which catalyses the biosynthesis of cysteine from acetylserine and sulfide, is involved in the sulfate-starvation response of E. coli. In this bacterium, reduced-sulfur limitation is known to derepress the genes of the cysteine biosynthetic pathway (Kredich, 1996). Based on sequence similarity with the SsuD protein from E. coli (63\% identity), SsuD of B. subtilis is probably a monooxygenase which catalyses the oxygenolytic conversion of sulfonates to sulfite and the 
corresponding aldehydes (Eichhorn et al., 1999). SsuA displays $32 \%$ identity with the aliphatic sulfonate binding protein of E. coli (van der Ploeg et al., 1999). In B. subtilis, the expression of the $s s u$ operon is repressed by sulfate and cysteine, while it is strongly induced by glutathione, taurine and methionine, and to a lesser extent by sulfonates (this work; van der Ploeg et al., 1998). In E. coli, the $s s u E A D C B$ operon (utilization of a broad range of sulfonates) and the tau $A B C D$ operon (utilization of taurine) are also upregulated in the absence of sulfate and cysteine (van der Ploeg et al., 1996, 1999). When sulfate and sulfonates are present, $E$. coli preferentially uses the inorganic sulfur source and represses the enzymes involved in the degradation of organosulfur compounds. Full expression of the genes involved in sulfonate utilization requires two LysR-type activators, CysB and Cbl (Kredich, 1996; IwanickaNowicka \& Hryniewicz, 1995).

The $y \mathrm{tmI}$ gene is located in a locus containing 12 genes which seem to form an operon. The ribR gene encodes a riboflavin kinase (Solovieva et al., 1999). Based on sequence similarities a potential function has been assigned to seven of these genes (Fig. 3). Five of them $(y t m J, y t m K, y t m L, y t m M$, hisP) are part of $\mathrm{ABC}$ transport systems. Interestingly, two different binding proteins, YtmJ and YtmK, are present, suggesting that this transport system is involved in the uptake of two different substrates. The $y$ tnJ gene product shares similarities with monooxygenases (30-40\% identity) and that of hipO with amino acid amidohydrolases (35-40\% identity). The functions of YtmI, YtmO and YtnM are unknown, while YtnI shares weak similarities with a putative glutaredoxin from Thermotoga maritima. The significant alteration in growth on taurine of a $y \mathrm{tmI}$ mutant suggests that at least one of these 12 genes plays a role in taurine assimilation. These genes are probably involved in the uptake and oxidation of alternative sulfur sources. The elucidation of their role in sulfur assimilation in B. subtilis deserves further investigation.

The $y \mathrm{tmI}$ gene is weakly expressed during growth with sulfate, cysteine and thiosulfate while its expression is strongly increased in the presence of glutathione, taurine and methionine. The $y t m J, y t m K, y t m M, y t n J$ and $y \operatorname{tn} M$ genes are regulated in the same way. We therefore propose that either some intermediary of the cysteine biosynthetic pathway mediates repression, or the expression of this operon is induced during sulfur limitation (glutathione and taurine) and in the presence of methionine.

Interestingly, YtlI, a LysR-type regulator, is the transcriptional activator of the $y \mathrm{tmI}$ operon. YtlI is the first regulator involved in the control of expression in response to sulfur availability to be identified in $B$. subtilis. In E. coli, three LysR-type proteins play a role in the regulation of sulfur metabolism: Cbl, CysB and MetR (Iwanicka-Nowicka \& Hryniewicz, 1995; Kredich, 1996; Greene, 1996). However, YtlI seems not to be involved in the global regulation of the sulfur limitation response in $B$. subtilis as it is not responsible for the regulation of serA, glyA, ssuA, cysK and yurL.

Several mechanisms for regulation of sulfur metabolism exist in B. subtilis. The S-box sequence involved in premature termination of transcription is found upstream of several genes involved in the methionine biosynthetic pathway (Grundy \& Henkin, 1998). In the present work, we have identified genes regulated in response to sulfur availability and the YtlI protein, a positive regulator of expression of the $y \mathrm{tmI}$ operon. The cysK, yurL, glyA and serA genes and the ssu operon are regulated by other mechanisms. The identification of other regulators is a challenging question for the future.

\section{ACKNOWLEDGEMENTS}

We thank Luis A. Rivas, Marie-Françoise Hullo, Itaï Yanai and Jerome Chapuis for the construction of some of the mutants used in this study, Hans-Henrik Saxild for the gift of strain LCC1, Claire Mulot for her excellent technical assistance, Ivan Moszer for helpful discussions, and Philippe Bertin and Carmen Buchreiser for careful reading of the manuscript.

This research was supported by LION BIOSCIENCE AG in the framework of a scientific collaboration, by grants from the Ministère de l'Education Nationale de la Recherche et de la Technologie, the Centre National de la Recherche Scientifique (URA 2171), the Institut Pasteur, the Université Paris 7 and the European Union Biotech Programme (contract ERBB104 CT960655).

\section{REFERENCES}

d'Aubenton Carafa, Y., Brody, E. \& Thermes, C. (1990). Prediction of Rho-independent Escherichia coli transcription terminators. A statistical analysis of their RNA stem-loop structures. J Mol Biol 216, 835-858.

Bernhardt, J., Büttner, K., Scharf, C. \& Hecker, M. (1999). Dual channel imaging of two-dimensional electropherograms in Bacillus subtilis. Electrophoresis 20, 2225-2240.

Danchin, A., Guerdoux-Janet, P., Moszer, I. \& Nitschke, P. (2000). Mapping the bacterial cell architecture into the chromosome. Philos Trans R Soc Lond B Biol Sci 355, 179-190.

Eichhorn, E., van der Ploeg, J. R. \& Leisinger, T. (1999). Characterization of a two-component alkanesulfonate monooxygenase from Escherichia coli. J Biol Chem 274, 26639-26646.

Ferrari, F. A., Nguyen, A., Lang, D. \& Hoch, J. A. (1983). Construction and properties of an integrable plasmid for Bacillus subtilis. J Bacteriol 154, 1513-1515.

Greene, R. C. (1996). Biosynthesis of methionine. In Escherichia coli and Salmonella: Cellular and Molecular Biology, pp. 542-560. Edited by F. C. Neidhardt and others. Washington, DC: American Society for Microbiology.

Grundy, F. J. \& Henkin, T. M. (1998). The $S$ box regulon: a new global transcription termination control system for methionine and cysteine biosynthesis genes in Gram-positive bacteria. Mol Microbiol 30, 737-749.

Hummerjohann, J., Kuttel, E. Quadroni, M., Ragaller, J., Leisinger, T. \& Kertesz, M. A. (1998). Regulation of the sulfate starvation response in Pseudomonas aeruginosa: role of cysteine biosynthetic intermediates. Microbiology 144, 1375-1386. 
Iwanicka-Nowicka, R. \& Hryniewicz, M. M. (1995). A new gene, $c b l$, encoding a member of the LysR family of transcriptional regulators belongs to Escherichia coli cys regulon. Gene 166, 11-17.

Kertesz, M. A., Leisinger, T. \& Cook, A. M. (1993). Proteins induced by sulfate limitation in Escherichia coli, Pseudomonas putida or Staphylococcus aureus. J Bacteriol 175, 1187-1190.

Kertesz, M. A., Schmidt-Larbig, K. \& Wuest, T. (1999). A novel reduced flavin mononucleotide-dependent methanesulfonate sulfonatase encoded by the sulfur-regulated $m s u$ operon of Pseudomonas aeruginosa. J Bacteriol 181, 1464-1473.

Kredich, N. M. (1996). Biosynthesis of cysteine. In Escherichia coli and Salmonella: Cellular and Molecular Biology, pp. 514-527. Edited by F. C. Neidhardt and others. Washington, DC: American Society for Microbiology.

Kunst, F. \& Rapoport, G. (1995). Salt stress is an environmental signal affecting degradative enzyme synthesis in Bacillus subtilis. J Bacteriol 177, 2403-2407.

Kunst, F., Ogasawara, N., Moszer, I. \& 148 other authors (1997). The complete genome sequence of the Gram-positive bacterium Bacillus subtilis. Nature 390, 249-256.

Mansilla, M. C. \& de Mendoza, D. (1997). L-Cysteine biosynthesis in Bacillus subtilis: identification, sequencing, and functional characterization of the gene coding for phosphoadenylylsulfate sulfotransferase. J Bacteriol 179, 976-981.

Mansilla, M. C. \& de Mendoza, D. (2000). The Bacillus subtilis cysP gene encodes a novel sulphate permease related to the inorganic phosphate transporter (Pit) family. Microbiology 146, 815-821.

Mathiopoulos, C., Mueller, J.P., Slack, F. J., Murphy, C. G., Patankar, S., Bukusoglu, G. \& Sonenshein, A. L. (1991). A Bacillus subtilis dipeptide transport system expressed early during sporulation. Mol Microbiol 5, 1903-1913.

Mazel, D. \& Marlière, P. (1989). Adaptative eradication of methionine and cysteine from cyanobacterial light-harvesting proteins. Nature 341, 245-248.

Meister, A, (1988). Glutathione metabolism and its selective modification. J Biol Chem 263, 17205-17208.

Miller, J. H. (1972). Assay of $\beta$-galactosidase. Experiments in Molecular Genetics, pp. 352-355. Edited by J. H. Miller. Cold Spring Harbor, NY: Cold Spring Harbor Laboratory.

O'Farrell, P. H. (1975). High resolution two-dimensional electrophoresis of proteins. J Biol Chem 250, 4007-4021.

Pasternak, C. A., Ellis, R. J., Jones-Mortimer, M. C. \& Crichton, C. E. (1965). The control of sulfate reduction in bacteria. Biochem J 96, 270-275.

van der Ploeg, J. R., Weiss, M. A., Saller, E., Nashimoto, H., Saito, N., Kertesz, M. A. \& Leisinger, T. (1996). Identification of sulfate starvation-regulated genes in Escherichia coli: a gene cluster involved in the utilization of taurine as a sulfur source. J Bacteriol 178, 5438-5446.

van der Ploeg, J. R., Iwanicka-Nowicka, R., Kertesz, M. A., Leisinger, T. \& Hryniewicz, M. M. (1997). Involvement of CysB and $\mathrm{Cbl}$ regulatory proteins in expression of the $\tan A B C D$ operon and other sulfate starvation-inducible genes in Escherichia coli. J Bacteriol 179, 7671-7678.

van der Ploeg, J. R., Cummings, N. J., Leisinger, T. \& Connerton, I. F. (1998). Bacillus subtilis genes for the utilization of sulfur from aliphatic sulfonates. Microbiology 144, 2555-2561.

van der Ploeg, J. R., Iwanicka-Nowicka, R., Bykowski, T., Hryniewicz, M. M. \& Leisinger, T. (1999). The Escherichia coli $s s u E A D C B$ gene cluster is required for the utilization of sulfur from aliphatic sulfonates and is regulated by the transcriptional activator Cbl. J Biol Chem 274, 29358-29365.

Quadroni, M., Staudenmann, W., Kertesz, M. \& James, P. (1996). Analysis of global responses by protein and peptide fingerprinting of proteins isolated by two-dimensional gel electrophoresis. Application to the sulfate-starvation response of Escherichia coli. Eur J Biochem 239, 773-781.

Quadroni, M., James, P., Dainese-Hatt, P. \& Kertesz, M. A. (1999). Proteome mapping, mass spectrometric sequencing and reverse transcription-PCR for characterization of the sulfate starvationinduced response in Pseudomonas aeruginosa PAO1. Eur J Biochem 266, 986-996.

Quentin, Y., Fichant, G. \& Denizot, F. (1999). Inventory, assembly and analysis of Bacillus subtilis $\mathrm{ABC}$ transport systems. J Mol Biol 287, 467-484.

Sambrook, J., Fritsch, E. F. \& Maniatis, T. (1989). Molecular Cloning: a Laboratory Manual, 2nd edn. Cold Spring Harbor, NY : Cold Spring Harbor Laboratory.

Sekowska, A., Kung, H. F. \& Danchin, A. (2000). Sulfur metabolism in Escherichia coli and related bacteria, facts and fiction. J Mol Microbiol Biotechnol 2, 145-177.

Shevchenko, A., Wilm, M., Vorm, O. \& Mann, M. (1996). Mass spectrometric sequencing of proteins from silver-stained polyacrylamide gels. Anal Chem 68, 850-858.

Solovieva, I. M., Kreneva, R. A., Leak, D. J. \& Perumov, D. A. (1999). The ribR gene encodes a monofunctional riboflavin kinase which is involved in regulation of the Bacillus subtilis riboflavin operon. Microbiology 145, 67-73.

Stülke, J., Martin-Verstraete, I., Zagorec, M., Rose, M., Klier, A. \& Rapoport, G. (1997). Induction of the Bacillus subtilis ptsGHI operon by glucose is controlled by a novel antiterminator, GlcT. Mol Microbiol 25, 65-78.

Uria-Nickelsen, M. R., Leadbetter, E. R. \& Godchaux, W. D., III (1993). Sulfonate-sulfur assimilation by yeasts resembles that of bacteria. FEMS Microbiol Lett 114, 73-77.

Vagner, V., Dervyn, E. \& Ehrlich, S. D. (1998). A vector for systematic gene inactivation in Bacillus subtilis. Microbiology 144, 3097-3104.

Wu, L. F., Reizer, A., Reizer, J., Cai, B., Tomich, J. M. \& Saier, M. H., Jr (1991). Nucleotide sequence of the Rhodobacter capsulatus fruK gene, which encodes fructose-1-phosphate kinase: evidence for a kinase superfamily including both phosphofructokinases of Escherichia coli. J Bacteriol 173, 3117-3127.

Received 17 November 2000; revised 16 February 2001; accepted 22 February 2001. 